\title{
Predictors of quality of life among individuals with schizophrenia
}

\author{
This article was published in the following Dove Press journal: \\ Neuropsychiatric Disease and Treatment \\ 28 May 2015 \\ Number of times this article has been viewed
}

\author{
Sirijit Suttajit \\ Sutrak Pilakanta \\ Department of Psychiatry, Faculty \\ of Medicine, Chiang Mai University, \\ Chiang Mai, Thailand
}

Purpose: The study reported here aimed to evaluate both biological and psychosocial factors as predictors for quality of life as well as to examine the associations between the factors and quality of life in individuals with schizophrenia.

Methods: Eighty individuals with schizophrenia were recruited to the study. The Thai version of the World Health Organization Quality of Life-BREF was utilized to measure the quality of life. The five Marder subscales of the Positive and Negative Syndrome Scale were applied. Other tools for measurement included the Calgary Depression Scale for Schizophrenia and six social support deficits (SSDs). Pearson/Spearman correlation coefficients and the independent $t$-test were used for the statistical analysis to determine the associations of variables and the overall quality of life and the four domain scores. A multiple linear regression analysis of the overall quality of life and four domain scores was applied to determine their predictors.

Results: The Positive and Negative Syndrome Scale total score, positive symptoms, negative symptoms, disorganized thought, and anxiety/depression showed a significant correlation with the overall quality of life and most of the four domain scores. Depression, SSDs, and adverse drug events showed a significant correlation with a poorer overall quality of life. The multiple linear regression model revealed that negative symptoms, depression, and seeing a relative less often than once per week were predictors for the overall quality of life (adjusted $R^{2}=0.472$ ). Negative symptoms were also found to be the main factors predicting a decrease in the four domains of quality of life - physical health, psychological, social relationships, and environment.

Conclusion: Negative symptoms, depression, and poor contact with relatives were the foremost predictors of poor quality of life in individuals with schizophrenia. Positive symptoms, negative symptoms, disorganized thought, anxiety/depression, SSDs, and adverse events were also found to be correlated with quality of life.

Keywords: adverse events, depression, negative symptoms, positive symptoms, social support

\section{Background}

The assessment of quality of life (QOL) has become a crucial outcome measure in individuals with severe mental disorders both in research and clinical practice. The evaluation of improvement in QOL, rather than a complete cure, encompasses a wide range of aspects associated with daily living. ${ }^{1}$ QOL has been related to functioning, access to resources, sense of well-being, and life satisfaction. ${ }^{2}$

QOL in individuals with schizophrenia has been measured from both subjective and objective points of view. Subjective measures of QOL include general indicators of life satisfaction and number of life domains such as satisfaction with work, family, social relations, finances, and housing situation. In addition, the objective measures of QOL usually include indicators of external life conditions, sociodemographic items, and a functioning role in society. ${ }^{2}$ The World Health Organization, however, focused
Correspondence: Sirijit Suttajit of Medicine, I 10 Intavaroros Road, Muang, Chiang Mai University, Chiang Mai 50200, Thailand

Tel +6653945422

Fax +6653945426

Email sirijits@gmail.com 
on the subjective aspect and defined QOL as the "individual's perception of their position in life in the context of culture and value systems in which they live and in relation to their goals, expectations, standards, and concerns". ${ }^{3}$

Biological factors, such as abnormal metabolic profiles, have also been of interest in individuals with schizophrenia. The prevalence of metabolic syndrome in individuals with schizophrenia was found to be higher than in the general population, at 40\%-60\% and $27 \%$, respectively. ${ }^{4}$ Vancampfort et al reported that an increased body mass index and lack of leisuretime physical activity were significantly related to impaired health-related quality of life (HRQOL). ${ }^{5}$ Our previous study found that metabolic syndrome had a significant association with depression, which is one of the most predictive factors for poor QOL in individuals with schizophrenia. ${ }^{6}$ Nevertheless, the Clinical Antipsychotic Trials of Intervention Effectiveness (CATIE) schizophrenia trial reported no significant difference in QOL between individuals with schizophrenia and metabolic syndrome and those with schizophrenia without metabolic syndrome. ${ }^{7}$

Antipsychotics are essential in the treatment of schizophrenia; however, the use of antipsychotics is associated with numerous side effects including drowsiness, sexual adverse events, dry mouth, insomnia, and extrapyramidal side effects. Atypical antipsychotics are believed to have fewer adverse effects than typical antipsychotics and, therefore, may lead to a better QOL. ${ }^{8}$ Additionally, drug-induced extrapyramidal side effects were reported to be negatively associated with QOL in individuals with schizophrenia. ${ }^{9}$

Several studies have evaluated the associations between psychosocial factors and QOL among individuals with schizophrenia. Negative symptoms were found to have a high correlation with QOL in most studies, ${ }^{2,10-13}$ while positive symptoms were found to be significantly associated with QOL in only some studies. ${ }^{10,11}$ Also, depression was found to be one of the most important factors in predicting a poor subjective QOL. ${ }^{14}$ Previous studies using depressive factors from the Positive and Negative Syndrome Scale (PANSS) and the Brief Psychiatric Rating Scale reported an association between depression and a poor QOL. ${ }^{15,16}$ However, one study compared QOL between individuals with schizophrenia with and without depression but did not find any significant differences. ${ }^{17}$

Social support may also act as a predictor for QOL in individuals with schizophrenia. Cohen et al found that the absence of loneliness and reliable social contacts were predictors for subjective well-being in individuals with schizophrenia. ${ }^{18}$ Another study reported that subjective social support accounted for life satisfaction. ${ }^{19}$ Our previous studies also found that social support deficits (SSDs) were significantly associated with depression and nonadherence in individuals with schizophrenia. ${ }^{20,21}$ Additionally, social support was reported to increase self-esteem, coping skills, and resilience as well as decreasing stigma. ${ }^{22}$

To the best of our knowledge, there has not been any study which has assessed both biological factors (eg, metabolic syndrome, type of antipsychotic, adverse events) and psychosocial factors (eg, psychopathology, social support, depression) as predictive factors of QOL in the same analysis. The study reported here aimed to evaluate the biopsychosocial factors as predictors for QOL as well as examining the correlations between the factors and QOL in individuals with schizophrenia.

\section{Methods}

\section{Sampling and data collection}

The study was approved by the Ethics Committee of the Faculty of Medicine, Chiang Mai University, Chiang Mai, Thailand. Eighty participants were recruited from the outpatient clinic of the Maharaj Nakorn Chiang Mai Hospital, Thailand. The inclusion criteria were Thai-speaking, age 18 years or over, and a diagnosis of schizophrenia according to the Diagnostic and Statistical Manual of Mental Disorders: Fourth Edition; Text Revision. ${ }^{23}$ The exclusion criterion was suffering from a neurological disorder that would interfere with the assessment. The details of the study were fully explained and written informed consent was obtained from all participants before the study.

\section{Measures \\ Dependent variable QOL}

We used the Thai version of the World Health Organization Quality of Life (WHOQOL)-BREF to measure the QOL, in which four domains are taken into account in rating the overall QOL: physical health, psychological, social relationships, and environment. ${ }^{24,25}$

\section{Independent variables \\ Metabolic profiles}

The metabolic measures were assessed based on an updated definition of metabolic syndrome derived from the modified National Cholesterol Education Program Adult Treatment Panel III criteria, those being: waist circumference, blood pressure (systolic and diastolic), triglyceride level, highdensity lipoprotein cholesterol, and fasting blood sugar. ${ }^{26}$ 


\section{Psychopathology}

Psychopathology was measured using the PANSS. The PANSS is a 30 -item, clinician-rated instrument covering psychotic and other psychiatric symptoms commonly found in individuals with schizophrenia. ${ }^{27,28}$ Each item is accompanied by a complete definition as well as detailed anchoring criteria for all seven rating points (from "absent" to "extremely severe"). Its rating is based on all information pertaining to a specified period during the previous week. The total PANSS score ranged from 30 to 210. As proposed by Marder et al, the five subscales of the PANSS were applied: positive symptoms, negative symptoms, disorganized thought, uncontrolled hostility/excitement, and anxiety/depression. ${ }^{29}$

\section{Depression}

Depression was evaluated using the Thai version of the Calgary Depression Scale for Schizophrenia (CDSS-Thai). The CDSS-Thai was validated and tested for the evaluation of depression in Thai individuals with schizophrenia with high internal consistency. The inter-rater reliability and the test-retest reliability were also high, with an intra-class correlation coefficient of 0.979 and 0.861 , respectively. ${ }^{30}$

\section{Social support}

Social support was derived from a scale of six SSDs. ${ }^{20}$ The six SSDs were defined as living alone, seeing a relative less often than once a week, lack of reciprocity with neighbors, lack of reciprocity between extended family members, difficulty in relationship(s) with one or more relatives, and dissatisfaction with support from family. Each item was scored as zero (deficit not present) or one (deficit present).

\section{Data analysis}

The IBM SPSS Statistics for Windows (version 22.0; IBM Corporation, Armonk, NY, USA) was used for all analyses. The normality of distribution of continuous data was checked with the Kolmogorov-Smirnov test. Correlations for normally distributed data were tested with Pearson's correlation coefficient while the correlations for non-normally distributed data were tested with Spearman's correlation. An independent $t$-test was used to evaluate the associations between sex, type of antipsychotic, adverse events, SSDs, and the overall QOL as well as the four domains.

Forward-selection multiple linear regression analyses of the overall QOL and four domain scores were applied to determine their predictors $(P$-value for entry $<0.05)$. Adjusted
$R^{2} \mathrm{~S}$ were analyzed to evaluate the ratio of the sum of squares explained by regression models. Coefficient values were used to quantify the strength of the associations. Statistical significance was defined as a $P$-value $<0.05$.

\section{Results}

Data collected from 80 (34 male and 46 female) participants with schizophrenia were analyzed. The mean values (standard deviations [SDs]) of age and duration of illness were 42.7 (14.1) years old and 13.6 (9.3) years, respectively (Table 1). Over $50 \%$ of the participants were prescribed with atypical antipsychotics (Table S1).

The mean values (SDs) of the total WHOQOL-BREF, physical health domain, psychological domain, social relationships domain, and environmental domain score are presented in Table 2.

\section{Correlations between biopsychosocial factors and QOL}

Bivariate analyses found that the PANSS total, positive symptoms, negative symptoms, and anxiety/depression showed significant correlation with the overall QOL (all $P$-values $<0.001)$ and all of the four domain scores. Depression, seeing a relative less often than once per week, lack of reciprocity with neighbors, and having adverse drug events (ie, memory loss, insomnia) were significantly correlated with a poorer overall QOL. Thirty-eight percent of the participants had metabolic syndrome but only fasting blood sugar was found to be significantly related to overall QOL and the physical health domain of QOL.

Participants with drowsiness were more likely to have poorer QOL in the physical health and psychological domains while dry mouth was associated with a poorer QOL in the physical health and social relationships domains. Occurrence of stiff tongue was found to be significantly related to lower scores of the psychological and social relationships domains of QOL, while presence of stiff walk significantly affected the environmental domain (Table 3).

\section{Multiple linear regression analyses}

The forward-selection multiple linear regression model revealed that negative symptoms, depression, and seeing a relative less often than once per week were predictors for overall QOL (adjusted $R^{2}=47.2 \%$ ). Negative symptoms were also found to be the main predicting factor for all domains of QOL, while depression was the main predictor for psychological and environmental domains (Table 4). 
Table I Baseline characteristics

\begin{tabular}{|c|c|}
\hline Characteristic/biopsychosocial factor & $\begin{array}{l}\text { Subjects } \\
(\mathbf{N}=80)\end{array}$ \\
\hline \multicolumn{2}{|l|}{$\operatorname{Sex}(n, \%)$} \\
\hline Male & $34(42.5)$ \\
\hline Female & $46(57.5)$ \\
\hline \multicolumn{2}{|l|}{ Marital status (n, \%) } \\
\hline Single & $52(63.4)$ \\
\hline Married & $19(23.2)$ \\
\hline Separated/divorced & $9(13.4)$ \\
\hline Age (years) (mean $\pm S D)$ & $42.7 \pm 14.1$ \\
\hline Duration of illness (years) (mean $\pm S D$ ) & $13.6 \pm 9.3$ \\
\hline \multicolumn{2}{|l|}{ Type of antipsychotic (n, \%) } \\
\hline Typical antipsychotics & $35(43.7)$ \\
\hline Atypical antipsychotics & $45(56.3)$ \\
\hline \multicolumn{2}{|l|}{ Adverse event $(n, \%)$} \\
\hline Drowsiness & $27(33.8)$ \\
\hline Sexual adverse events & $8(11.1)$ \\
\hline Memory loss & $25(31.3)$ \\
\hline Dry mouth & $18(22.5)$ \\
\hline Drooling & $13(16.3)$ \\
\hline Insomnia & $17(2 \mid .3)$ \\
\hline Stiff tongue & $12(15.0)$ \\
\hline Stiff walk & $7(8.8)$ \\
\hline \multicolumn{2}{|l|}{ Metabolic profile (mean \pm SD) } \\
\hline Waist circumference $(\mathrm{cm})$ & $86.4 \pm 10.5$ \\
\hline Fasting blood sugar (mg/dL) & $103.7 \pm 33.1$ \\
\hline Triglycerides (mg/dL) & $|3| .4 \pm 98.9$ \\
\hline High-density lipoprotein (mg/dL) & $54.5 \pm 12.8$ \\
\hline Systolic blood pressure $(\mathrm{mmHg})$ & $122.3 \pm 15.3$ \\
\hline Diastolic blood pressure $(\mathrm{mmHg})$ & $79.3 \pm 10.4$ \\
\hline \multicolumn{2}{|l|}{ PANSS score (mean \pm SD) } \\
\hline PANSS total & $45.6 \pm 12.6$ \\
\hline PANSS Marder positive symptoms & $12.7 \pm 4.6$ \\
\hline PANSS Marder negative symptoms & $11.0 \pm 4.2$ \\
\hline PANSS Marder disorganized thought & $9.8 \pm 3.3$ \\
\hline PANSS Marder hostility/excitement & $5.4 \pm 1.4$ \\
\hline PANSS Marder anxiety/depression & $6.8 \pm 2.8$ \\
\hline CDSS-Thai score (mean \pm SD) & $3.9 \pm 4.3$ \\
\hline \multicolumn{2}{|l|}{ Social support deficit (n, \%) } \\
\hline Living alone & II (I3.4) \\
\hline Seeing a relative less often than once a week & $8(9.8)$ \\
\hline Lack of reciprocity with neighbors & $9(11.0)$ \\
\hline Lack of reciprocity between family members & II (I3.4) \\
\hline Difficulty in relationship with relatives & $7(8.5)$ \\
\hline Dissatisfaction with support from family & $5(6.1)$ \\
\hline
\end{tabular}

Abbreviations: CDSS-Thai, Thai version of the Calgary Depression Scale for Schizophrenia; PANSS, Positive and Negative Syndrome Scale; SD, standard deviation.

\section{Discussion}

Our findings indicate that psychosocial factors, especially negative symptoms, depression, and social support, are the main predictors for QOL in individuals with schizophrenia. Biological factors, although found to be significantly related to QOL, were not major predictors.

\section{Baseline characteristics and $\mathrm{QOL}$}

No significant association between QOL and sex, age, education, or duration of illness was found. These findings are in
Table 2 The World Health Organization Quality of Life-BREF (WHOQOL-BREF) scores for quality of life

\begin{tabular}{ll}
\hline Domain & Score (mean \pm SD) \\
\hline Total & $90.4 \pm 15.2$ \\
Physical health & $24.3 \pm 4.4$ \\
Psychological & $21.6 \pm 4.3$ \\
Social relationships & $10.0 \pm 2.2$ \\
Environment & $27.9 \pm 4.9$ \\
\hline
\end{tabular}

Abbreviation: SD, standard deviation.

line with the study of Holloway and Carson which reported that personal and sociodemographic characteristics were weakly associated or not associated with global subjective well-being. ${ }^{31}$

\section{Biological factors and QOL Metabolic profiles}

Only high fasting blood sugar was found to be significantly associated with overall QOL and the physical health domain of QOL while other metabolic profiles were not significantly related to QOL. The results of this study support the notion that some abnormal metabolic profiles are related to a poor QOL. Foldemo et al reported that elevated blood pressure and raised low-density lipoprotein cholesterol were related to lower HRQOL..$^{32}$ In addition, Vancampfort et al suggested that lower HRQOL seemed to be associated with a higher body mass index and lack of physical activity, rather than to metabolic syndrome per se. ${ }^{5}$ However, the findings from this study were in contrast with those from the CATIE study which showed no significant association between metabolic syndrome and QOL. ${ }^{33}$

\section{Antipsychotics and adverse events}

Typical antipsychotics were reported in previous studies to have more adverse events than atypical ones. ${ }^{8}$ The results of this study show that adverse events, including drowsiness, memory loss, dry mouth, insomnia, stiff tongue, and stiff walk, were significantly related to several domains of QOL, but typical antipsychotics were significantly associated with poorer QOL only in the environmental domain. These findings are consistent with a recent study which found that side effects rather than type of pharmacotherapy were associated with QOL. ${ }^{13,34}$ The CATIE study, although focused on life satisfaction rather than QOL, reported similar significant relationships between adverse events (eg, dry mouth, insomnia, sleepiness) and life satisfaction. ${ }^{35}$

In the study reported here, individuals with drowsiness and insomnia were more likely to have a poor QOL in the 
Table 3 Correlations between demographic characteristics, biopsychosocial factors, and quality of life

\begin{tabular}{|c|c|c|c|c|c|c|}
\hline \multirow[t]{2}{*}{ Item } & \multicolumn{5}{|c|}{ Quality of life } & \multirow[t]{2}{*}{ Statistic } \\
\hline & Total & $\begin{array}{l}\text { Physical } \\
\text { health }\end{array}$ & Psychological & $\begin{array}{l}\text { Social } \\
\text { relationships }\end{array}$ & Environment & \\
\hline Sex & -0.253 & 0.403 & -0.305 & -0.230 & -0.815 & Independent $t$ \\
\hline Age (years) & -0.139 & -0.182 & -0.076 & -0.029 & -0.078 & Pearson's $r$ \\
\hline Education (years) & 0.075 & 0.024 & 0.056 & 0.092 & 0.077 & Spearman's $r$ \\
\hline Duration of illness (years) & 0.093 & 0.004 & 0.128 & 0.035 & 0.113 & Pearson's $r$ \\
\hline \multicolumn{7}{|l|}{ Biological factor } \\
\hline Type of antipsychotic & -1.073 & 0.041 & -1.024 & -0.372 & $-2.05 \mathrm{I} *$ & Independent $t$ \\
\hline \multicolumn{7}{|l|}{ Adverse events } \\
\hline Drowsiness & 1.927 & $2.022 *$ & $2.189 *$ & 1.498 & 1.569 & Independent $t$ \\
\hline Sexual adverse events & 1.250 & 0.294 & 1.272 & $\mathrm{I} .535$ & 1.962 & Independent $t$ \\
\hline Memory loss & $2.958^{* *}$ & $2.759 * *$ & $2.916 * *$ & $3.754 * * *$ & 1.976 & Independent $t$ \\
\hline Dry mouth & $\mathrm{I} .727$ & $2.021 *$ & 1.761 & $2.262^{*}$ & 0.860 & Independent $t$ \\
\hline Drooling & 1.377 & 1.338 & 1.286 & 1.302 & 1.062 & Independent $t$ \\
\hline Insomnia & $2.883 * *$ & $2.18 I^{*}$ & $2.870 * *$ & $\mathrm{I} .532$ & $2.86 I^{* *}$ & Independent $t$ \\
\hline Stiff tongue & $1.67 \mid$ & 1.807 & $2.123^{*}$ & $2.244^{*}$ & 0.777 & Independent $t$ \\
\hline Stiff walk & 1.443 & 0.789 & 1.560 & 1.569 & $2.878 *$ & Independent $t$ \\
\hline \multicolumn{7}{|l|}{ Metabolic profile (mean \pm SD) } \\
\hline Waist circumference $(\mathrm{cm})$ & -0.069 & -0.113 & -0.081 & -0.137 & 0.032 & Pearson's $r$ \\
\hline Fasting blood sugar $(\mathrm{mg} / \mathrm{dL})$ & $-0.239 *$ & $-0.338^{* *}$ & -0.192 & -0.216 & -0.150 & Spearman's $r$ \\
\hline Triglycerides (mg/dL) & -0.084 & 0.102 & 0.052 & 0.054 & 0.079 & Spearman's $r$ \\
\hline High-density lipoprotein (mg/dL) & 0.051 & 0.067 & 0.104 & 0.113 & -0.032 & Pearson's $r$ \\
\hline Systolic blood pressure (mmHg) & -0.067 & -0.050 & 0.007 & -0.108 & -0.084 & Pearson's $r$ \\
\hline Diastolic blood pressure $(\mathrm{mmHg})$ & 0.033 & 0.002 & 0.096 & -0.086 & 0.061 & Pearson's $r$ \\
\hline \multicolumn{7}{|l|}{ Psychosocial factor } \\
\hline \multicolumn{7}{|l|}{ PANSS score } \\
\hline PANSS total & $-0.599 * * *$ & $-0.522 * * *$ & $-0.658 * * *$ & $-0.510 * * *$ & $-0.462 * * *$ & Pearson's $r$ \\
\hline $\begin{array}{l}\text { PANSS Marder positive } \\
\text { symptoms }\end{array}$ & $-0.444 * * *$ & $-0.412^{* * *}$ & $-0.49 I^{* * *}$ & $-0.318^{* *}$ & $-0.348^{* *}$ & Spearman's $r$ \\
\hline $\begin{array}{l}\text { PANSS Marder negative } \\
\text { symptoms }\end{array}$ & $-0.620 * * *$ & $-0.555^{* * *}$ & $-0.644^{* * *}$ & $-0.533 * * *$ & $-0.497 * * *$ & Spearman's $r$ \\
\hline $\begin{array}{l}\text { PANSS Marder disorganized } \\
\text { thought }\end{array}$ & $-0.400 * * *$ & $-0.333^{* *}$ & $-0.429 * * *$ & $-0.446 * * *$ & $-0.28 I^{*}$ & Spearman's $r$ \\
\hline $\begin{array}{l}\text { PANSS Marder hostility/ } \\
\text { excitement }\end{array}$ & -0.195 & -0.177 & $-0.262^{*}$ & -0.213 & -0.108 & Spearman's $r$ \\
\hline $\begin{array}{l}\text { PANSS Marder anxiety/ } \\
\text { depression }\end{array}$ & $-0.489 * * *$ & $-0.385 * * *$ & $-0.576 * * *$ & $-0.362 * * *$ & $-0.390 * * *$ & Spearman's $r$ \\
\hline CDSS-Thai score & $-0.580 * * *$ & $-0.459 * * *$ & $-0.644 * * *$ & $-0.390 * * *$ & $-0.511 * * *$ & Spearman's $r$ \\
\hline \multicolumn{7}{|l|}{ Social support deficit } \\
\hline Living alone & 0.656 & -0.008 & 0.686 & 0.521 & 1.149 & Independent $t$ \\
\hline $\begin{array}{l}\text { Seeing a relative less often than } \\
\text { once a week }\end{array}$ & $2.603^{*}$ & $2.257^{*}$ & 1.970 & $3.224 * *$ & $2.570^{*}$ & Independent $t$ \\
\hline $\begin{array}{l}\text { Lack of reciprocity with } \\
\text { neighbors }\end{array}$ & $2.292 *$ & 1.564 & $2.629 * *$ & 1.223 & $2.505^{*}$ & Independent $t$ \\
\hline $\begin{array}{l}\text { Lack of reciprocity between } \\
\text { family members }\end{array}$ & 1.974 & 0.724 & $2.658^{* *}$ & 0.376 & $2.494^{*}$ & Independent $t$ \\
\hline $\begin{array}{l}\text { Difficulty in relationship with } \\
\text { relatives }\end{array}$ & 0.572 & 0.342 & 1.091 & -1.116 & 0.769 & Independent $t$ \\
\hline $\begin{array}{l}\text { Dissatisfaction with support from } \\
\text { family }\end{array}$ & 1.953 & 0.867 & $2.045^{*}$ & $2.080^{*}$ & $1.996 *$ & Independent $t$ \\
\hline
\end{tabular}

Notes: *Significant at $P$-value $<0.05$ (two-tailed); **significant at $P$-value $<0.01$ (two-tailed); *** significant at $P$-value $<0.00 \mathrm{I}$ (two-tailed).

Abbreviations: CDSS-Thai, Thai version of the Calgary Depression Scale for Schizophrenia; PANSS, Positive and Negative Syndrome Scale; SD, standard deviation.

physical health and psychological domains. Memory loss was also found to have a deleterious impact on the physical health and psychological domains of QOL as well as the social relationships domain. This might be explained by the fact that memory loss reflects poor cognitive function in individuals with more severe schizophrenia. Furthermore, this finding is consistent with a study from Asia which demonstrated that working memory and verbal memory showed a strong correlation with the physical domain of QOL. ${ }^{36}$ 
Table 4 Forward-selection multiple linear regression models with the total and the four domain scores of quality of life as dependent variables

\begin{tabular}{|c|c|c|c|c|c|c|c|c|}
\hline Step & Independent variable & B & SE & $\beta$ & $t$ & $P$-value & $\begin{array}{l}R^{2} \\
\text { change }\end{array}$ & $\begin{array}{l}\text { Model } \\
\text { adjusted } R^{2}\end{array}$ \\
\hline \multicolumn{8}{|c|}{ Model I: QOL total as dependent variable } & $47.2 \%$ \\
\hline I & PANSS Marder negative symptoms & -1.490 & 0.363 & -0.410 & -4.101 & $<0.001$ & 0.384 & \\
\hline 2 & CDSS-Thai & -1.143 & 0.353 & -0.322 & -3.234 & 0.002 & 0.076 & \\
\hline 3 & Seeing a relative less often than once a week & -9.031 & 4.172 & -0.179 & -2.164 & 0.034 & 0.031 & \\
\hline \multicolumn{8}{|c|}{ Model 2: QOL physical health as dependent variable } & $29.9 \%$ \\
\hline I & PANSS Marder negative symptoms & -0.587 & 0.100 & -0.555 & -5.892 & $<0.00$ I & 0.308 & \\
\hline \multicolumn{8}{|c|}{ Model 3: QOL psychological as dependent variable } & $53.8 \%$ \\
\hline I & PANSS Marder negative symptoms & -0.419 & 0.096 & -0.404 & -4.340 & $<0.001$ & 0.415 & \\
\hline 2 & CDSS-Thai & -0.401 & 0.094 & -0.397 & -4.250 & $<0.001$ & 0.114 & \\
\hline 3 & Drowsiness & -1.505 & 0.701 & -0.165 & -2.148 & 0.044 & 0.027 & \\
\hline \multicolumn{8}{|c|}{ Model 4: QOL social relationships as dependent variable } & $35.5 \%$ \\
\hline I & PANSS Marder negative symptoms & -0.196 & 0.057 & -0.366 & -3.456 & 0.001 & 0.288 & \\
\hline 2 & Memory loss & -1.085 & 0.460 & -0.227 & -2.356 & 0.021 & 0.058 & \\
\hline 3 & PANSS Marder disorganized thought & -0.145 & 0.071 & -0.212 & -2.027 & 0.046 & 0.034 & \\
\hline \multicolumn{8}{|c|}{ Model 5: QOL environment as dependent variable } & $36.7 \%$ \\
\hline I & CDSS-Thai & -0.400 & 0.125 & -0.289 & -3.210 & 0.002 & 0.261 & \\
\hline 2 & PANSS Marder negative symptoms & -0.283 & 0.129 & -0.265 & -2.195 & 0.031 & 0.063 & \\
\hline 3 & Atypical antipsychotics & 1.935 & 0.885 & -0.224 & 2.185 & 0.032 & 0.041 & \\
\hline 4 & Seeing a relative less often than once a week & -3.034 & 1.461 & -0.189 & -2.076 & 0.041 & 0.035 & \\
\hline
\end{tabular}

Note: Forward selection, probability-of-F-to-enter $\leq 0.05$.

Abbreviations: CDSS-Thai, Thai version of the Calgary Depression Scale for Schizophrenia; PANSS, Positive and Negative Syndrome Scale; QOL, quality of life; SE, standard error.

\section{Psychosocial factors and QOL}

\section{Psychopathology}

The results from this study are in line with those of previous studies which reported that negative symptoms affected QOL more than positive symptoms. ${ }^{2,10,36}$ Although our bivariate analyses found a significant association between positive symptoms and QOL, the correlation was not significant, after adjustment for several variables in the regression models. This is in line with a meta-analysis which suggested that positive symptoms had a poor correlation with QOL. ${ }^{37}$

Narvaez et al suggested that more severe negative symptoms predicted a lower objective QOL while more severe depressive symptoms were predictors of worse subjective QOL. ${ }^{38}$ In this study, however, negative symptoms and depression were the main predictors affecting the subjective QOL.

\section{Depression}

In this study, depression showed a strong significant association with QOL in every domain and was a predictor for poor environmental and psychological QOL in individuals with schizophrenia. Our findings support the idea that depression is one of the most significant factors for predicting poor QOL in individuals with schizophrenia. ${ }^{14}$ Depression may be associated with a worse QOL due to poor living conditions. ${ }^{38}$ Furthermore, individuals with depression who have poor self-esteem and a negative view of themselves may rate their QOL worse than those without depression. Morgado et al reported that individuals with depression rated their functioning and living conditions at a lower level than an external observer and even themselves after recovery. ${ }^{39}$

Our findings contradict those reported in a recent study which did not find a significant difference in QOL between those with and without depression. ${ }^{17}$ The discrepancy might be due to a difference in the severity of the depression in the sample, since most of the population in the previous study had mild depression and only participants with at least one caregiver were included; therefore, those participants might have had less severe depression and better social support compared to those in this study. ${ }^{17}$

\section{Social support}

In Thai culture, the focus of this paper, individuals with schizophrenia generally live with their family members, thus they receive financial as well as emotional support from their family. We found that lack of contact with relatives and lack of reciprocity with neighbors both had a significant association with poor overall QOL. Lack of contact with relatives was also found to be a predictor for poor environmental QOL. Our findings are in line with a previous study which reported that attachment and reassurance of worth were predictors for 
improving QOL in schizophrenia. ${ }^{40}$ The CATIE study also suggested that interpersonal relationships had great influence on the level of life satisfaction. ${ }^{35}$ Moreover, the availability and adequacy of social support was found to be related to satisfaction with life in individuals with severe mental illness. ${ }^{41}$ Social support may improve QOL by stress-buffering, reducing depression, and enhancing the adaptation process..$^{20,40}$ Our study suggests that lack of contact with relatives is one of the main predictors for overall QOL, even after adjusting for psychopathology and depression.

\section{Limitations}

Although this study leads to better understanding of the predictors for QOL in individuals with schizophrenia, some limitations should be taken into consideration when interpreting the findings from this study. First, the direction of causality among variables cannot be determined due to the cross-sectional study design. It is possible that there might be a vicious cycle whereby factors such as depression may cause a poor QOL which, in turn, may worsen depression.

Second, the WHOQOL-BREF mainly focuses on the subjective domain of QOL which may lead to lack of the objective measure and an over-reporting of QOL in individuals with schizophrenia. However, it is generally agreed that individuals whose symptoms are stable can assess their QOL by themselves. ${ }^{14}$ Moreover, a subjective domain of QOL has been considered a core component of assessing QOL, since an individual's perception of his/her condition represents a complete picture of the person's life. ${ }^{42}$

Third, there may be some overlap in the evaluation of depression and negative symptoms of schizophrenia $(r=0.228) .{ }^{43}$ However, the CDSS-Thai has been validated to exclude depression from the negative symptoms which clarifies the results of the study. ${ }^{30}$ In addition, the results from this study show that both depression and negative symptoms are independent predictors, even after being adjusted in the regression analyses.

Fourth, the small sample size might limit the positive findings.

Lastly, since this study was conducted at an outpatient clinic in Thailand, the findings from this study might have a lack of generalizability to other individuals with more severe symptoms in other settings.

\section{Conclusion}

Negative symptoms, depression, and poor contact with relatives were the main predictors for QOL in this sample.
Positive symptoms, disorganized thought, SSDs, increased fasting blood sugar, and some adverse events may also have correlation with QOL. This study suggests that depression and the adverse events of antipsychotics should be carefully monitored in individuals with schizophrenia, as they might affect QOL. Antipsychotic medications with the efficacy of reducing negative symptoms, depression, and fewer adverse events, especially in cognitive impairment, should be considered in the treatment of schizophrenia. Increased social support from family members and psychosocial treatment which involves the family, such as family therapy and interventions that increase reciprocity with family members and neighbors, are imperative in the enhancement of QOL. Further prospective studies should be conducted in other settings with different cultures and in larger populations to extend the knowledge and inform the possibility of the treatment of individuals suffering from schizophrenia.

\section{Acknowledgment}

This study was supported by a grant from the Faculty of Medicine, Chiang Mai University.

\section{Disclosure}

The authors declare no conflicts of interest in this work.

\section{References}

1. Oliver J, Huxley P, Bridges K, Mohamad H. Quality of Life and Mental Health Services. London: Routledge; 1996.

2. Fitzgerald PB, Williams CL, Corteling N, et al. Subject and observerrated quality of life in schizophrenia. Acta Psychiatr Scand. 2001;103(5): 387-392.

3. Saxena S, Orley J; WHOQOL Group. Quality of life assessment: The world health organization perspective. Eur Psychiatry. 1997;12 Suppl 3: $263 \mathrm{~s}-266 \mathrm{~s}$

4. von Hausswolff-Juhlin Y, Bjartveit M, Lindstrom E, Jones P. Schizophrenia and physical health problems. Acta Psychiatr Scand Suppl. 2009(438):15-21.

5. Vancampfort D, Probst M, Scheewe T, et al. Lack of physical activity during leisure time contributes to an impaired health related quality of life in patients with schizophrenia. Schizophr Res. 2011;129(2-3): $122-127$.

6. Suttajit S, Pilakanta S. Prevalence of metabolic syndrome and its association with depression in patients with schizophrenia. Neuropsychiatr Dis Treat. 2013;9:941-946.

7. McEvoy JP, Meyer JM, Goff DC, et al. Prevalence of the metabolic syndrome in patients with schizophrenia: baseline results from the Clinical Antipsychotic Trials of Intervention Effectiveness (CATIE) schizophrenia trial and comparison with national estimates from NHANES III. Schizophr Res. 2005;80(1):19-32.

8. Suttajit S, Srisurapanont M, Xia J, Maneeton B, Maneeton N. Quetiapine versus typical antipsychotic medications for schizophrenia. Cochrane Database Syst Rev. 2013;5:CD007815.

9. Xiang YT, Weng YZ, Leung CM, Tang WK, Ungvari GS. Quality of life of Chinese schizophrenia outpatients in Hong Kong: relationship to sociodemographic factors and symptomatology. Aust N Z J Psychiatry. 2007;41(5):442-449. 
10. Norman RM, Malla AK, McLean T, et al. The relationship of symptoms and level of functioning in schizophrenia to general wellbeing and the Quality of Life Scale. Acta Psychiatr Scand. 2000;102(4):303-309.

11. Bow-Thomas CC, Velligan DI, Miller AL, Olsen J. Predicting quality of life from symptomatology in schizophrenia at exacerbation and stabilization. Psychiatry Res. 1999;86(2):131-142.

12. Browne S, Garavan J, Gervin M, Roe M, Larkin C, O'Callaghan E. Quality of life in schizophrenia: insight and subjective response to neuroleptics. J Nerv Ment Dis. 1998;186(2):74-78.

13. Browne S, Roe M, Lane A, et al. Quality of life in schizophrenia: relationship to sociodemographic factors, symptomatology and tardive dyskinesia. Acta Psychiatr Scand. 1996;94(2):118-124.

14. Tomotake M. Quality of life and its predictors in people with schizophrenia. J Med Invest. 2011;58(3-4):167-174.

15. Dickerson FB, Ringel NB, Parente F. Subjective quality of life in outpatients with schizophrenia: clinical and utilization correlates. Acta Psychiatr Scand. 1998;98(2):124-127.

16. Huppert JD, Weiss KA, Lim R, Pratt S, Smith TE. Quality of life in schizophrenia: contributions of anxiety and depression. Schizophr Res. 2001;51(2-3):171-180.

17. Dan A, Kumar S, Avasthi A, Grover S. A comparative study on quality of life of patients of schizophrenia with and without depression. Psychiatry Res. 2011;189(2):185-189.

18. Cohen CI, Talavera N, Hartung R. Predictors of subjective well-being among older, community-dwelling persons with schizophrenia. Am J Geriatr Psychiatry. 1997;5(2):145-155.

19. Clinton M, Lunney P, Edwards H, Weir D, Barr J. Perceived social support and community adaptation in schizophrenia. J Adv Nurs. 1998; 27(5):955-965.

20. Suttajit S, Punpuing S, Jirapramukpitak T, et al. Impairment, disability, social support and depression among older parents in rural Thailand. Psychol Med. 2010;40(10):1711-1721.

21. Suttajit S, Pilakanta S. Prevalence of and factors associated with depression in patients with schizophrenia in Thailand: a post-hoc analysis. Chiang Mai Medical Journal. 2011;50(4):115-121.

22. Hardy SE, Concato J, Gill TM. Resilience of community-dwelling older persons. J Am Geriatr Soc. 2004;52(2):257-262.

23. American Psychiatric Association (APA). Diagnostic and Statistical Manual of Mental Disorders: Fourth Edition; Text Revision. Washington DC: APA; 2000.

24. Mahatnirunkul S, Tuntipivatanaskul W, Pumpisanchai W. [Comparison of the WHOQOL-100 and the WHOQOL-BREF (26 items)]. J Ment Health Thai. 1998;5:4-15. Thai.

25. Development of the World Health Organization WHOQOL-BREF quality of life assessment. The WHOQOL Group. Psychol Med. 1998;28(3): $551-558$.

26. Grundy SM, Cleeman JI, Daniels SR, et al; American Heart Association; National Heart, Lung, and Blood Institute. Diagnosis and management of the metabolic syndrome: an American Heart Association/National Heart, Lung, and Blood Institute Scientific Statement. Circulation. 2005;112(17):2735-2752.

27. Kay SR, Fiszbein A, Opler LA. The positive and negative syndrome scale (PANSS) for schizophrenia. Schizophr. Bull. 1987;13(2):261-276.
28. Kay SR, Opler LA, Lindenmayer JP. Reliability and validity of the positive and negative syndrome scale for schizophrenics. Psychiatry Res.1988; 23(1):99-110.

29. Marder SR, Davis JM, Chouinard G. The effects of risperidone on the five dimensions of schizophrenia derived by factor analysis: combined results of the North American trials. J Clin Psychiatry. 1997;58(12): $538-546$.

30. Suttajit S, Srisurapanont M, Pilakanta S, Charnsil C, Suttajit S. Reliability and validity of the Thai version of the Calgary Depression Scale for Schizophrenia. Neuropsychiatr Dis Treat. 2013;9:113-118.

31. Holloway F, Carson J. Quality of life in severe mental illness. Int Rev Psychiatry. 2002;14(3):175-184.

32. Foldemo A, Wärdig R, Bachrach-Lindström M, et al. Health-related quality of life and metabolic risk in patients with psychosis. Schizophr Res. 2014;152(1):295-299.

33. Meyer JM, Nasrallah HA, McEvoy JP, et al. The Clinical Antipsychotic Trials Of Intervention Effectiveness (CATIE) Schizophrenia Trial: clinical comparison of subgroups with and without the metabolic syndrome. Schizophr Res. 2005;80(1):9-18.

34. Wehmeier PM, Kluge M, SchneiderE, Schacht A, WagnerT, Schreiber W. Quality of life and subjective well-being during treatment with antipsychotics in out-patients with schizophrenia. Prog Neuropsychopharmacol Biol Psychiatry. 2007;31(3):703-712.

35. Fervaha G, Agid O, Takeuchi H, Foussias G, Remington G. Life satisfaction among individuals with schizophrenia in the Clinical Antipsychotic Trial of Intervention Effectiveness (CATIE) study. Am J Psychiatry. 2014;170(9):1061-1062.

36. Woon PS, Chia MY, Chan WY, Sim K. Neurocognitive, clinical and functional correlates of subjective quality of life in Asian outpatients with schizophrenia. Prog Neuropsychopharmacol Biol Psychiatry. 2010;34(3):463-468.

37. Eack SM, Newhill CE. Psychiatric symptoms and quality of life in schizophrenia: a meta-analysis. Schizophr Bull. 2007;33(5):1225-1237.

38. Narvaez JM, Twamley EW, McKibbin CL, Heaton RK, Patterson TL. Subjective and objective quality of life in schizophrenia. Schizophr Res.2008; 98(1-3):201-208.

39. Morgado A, Smith M, Lecrubier Y, Widlöcher D. Depressed subjects unwittingly overreport poor social adjustment which they reappraise when recovered. J Nerv Ment Dis. 1991;179(10):614-619.

40. Caron J, Lecomte Y, Stip E, Renaud S. Predictors of quality of life in schizophrenia. Community Ment Health J. 2005;41(4):399-417.

41. Baker F, Jodrey D, Intagliata J. Social support and quality of life of community support clients. Community Ment Health J. 1992;28(5): $397-411$.

42. Ruggeri M, Bisoffi G, Fontecedro L, Warner R. Subjective and objective dimensions of quality of life in psychiatric patients: a factor analytical approach: The South Verona Outcome Project 4. Br J Psychiatry. 2001; 178:268-275.

43. Collins AA, Remington G, Coulter K, Birkett K. Depression in schizophrenia: a comparison of three measures. Schizophr Res. 1996;20(1-2): 205-209. 


\section{Supplementary material}

Table SI Types of antipsychotic medications $(\mathrm{N}=80)$

\begin{tabular}{ll}
\hline Type of antipsychotic medication & $\mathbf{n}(\%)$ \\
\hline Typical antipsychotic & \\
Perphenazine & $\mathrm{I}(20.0)$ \\
Haloperidol & $\mathrm{I} 5(\mathrm{I} 8.8)$ \\
Chlorpromazine & $3(3.8)$ \\
Thioridazine & $\mathrm{I}(\mathrm{I} .2)$ \\
Atypical antipsychotic & \\
Risperidone & $23(28.8)$ \\
Clozapine & $\mathrm{II}(\mathrm{I} .8)$ \\
Aripiprazole & $5(6.2)$ \\
Quetiapine & $4(5.0)$ \\
Paliperidone & $\mathrm{I}(\mathrm{I} .2)$ \\
Olanzapine & $\mathrm{I}(\mathrm{I} .2)$ \\
\hline
\end{tabular}

\section{Publish your work in this journal}

Neuropsychiatric Disease and Treatment is an international, peerreviewed journal of clinical therapeutics and pharmacology focusing on concise rapid reporting of clinical or pre-clinical studies on a range of neuropsychiatric and neurological disorders. This journal is indexed on PubMed Central, the 'PsycINFO' database and CAS, and is the official journal of The International Neuropsychiatric Association (INA). The manuscript management system is completely online and includes a very quick and fair peer-review system, which is all easy to use. Visit http://www.dovepress.com/testimonials.php to read real quotes from published authors.

\footnotetext{
Submit your manuscript here: http://www.dovepress.com/neuropsychiatric-disease-and-treatment-journal
} 